Check for updates

Cite this: RSC Adv., 2018, 8, 26069

\title{
Osteogenic capacity of mixed-acid and heat- treated titanium mesh prepared by a selective laser melting technique
}

\author{
Kayoko Yamamoto, (D) *a Seiji Yamaguchi, ${ }^{\mathrm{b}}$ Tomiharu Matsushita, ${ }^{\mathrm{b}}$ Shigeo Mori, ${ }^{\mathrm{c}}$ \\ Azumi Hirata, ${ }^{d}$ Nahoko Kato-Kogoe, (D) ${ }^{a}$ Hiroyuki Nakano, ${ }^{a}$ Yoichiro Nakajima, ${ }^{a}$

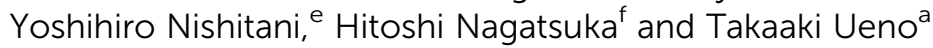

\begin{abstract}
The practical use of additive manufacturing to create artificial bone as a material for repairing complex bone defects is currently attracting attention. In this study, we compared the osteogenic capacity of materials composited by the method developed by Kokubo et al. of treating 3D-printed titanium (Ti) mesh with a mixture of $\mathrm{H}_{2} \mathrm{SO}_{4}$ and $\mathrm{HCl}$ and heating (mixed-acid and heat treatment) with that of materials subjected to conventional chemical treatment. Ti plates treated with this method have been found to promote highly active bone formation on their surface when inserted into rabbit tibial bone defects. No previous study has compared this method with other surface treatment methods. In this study, we used histological and other observations to compare the bone formation process in bone defects when Ti meshes prepared by the selective laser melting technique (SLM) and treated either with mixed acids and heat or with conventional chemical Ti surface treatments were implanted in a rat calvarial bone defect model. We found that both micro-computed tomography and observations of undecalcified ground sections showed that the best bone formation was observed in rats implanted with mesh treated with mixed acids and heat. Our results suggest

that mixed-acid and heat-treated Ti mesh prepared by SLM may have a high osteogenic capacity in bone defects.
\end{abstract}

Received 16th May 2018 Accepted 11th July 2018

DOI: $10.1039 / \mathrm{c} 8 \mathrm{ra0} 4193 \mathrm{~h}$

rsc.li/rsc-advances

\section{Introduction}

The high bioaffinity of titanium (Ti) means it is widely used in medical applications including endovascular stents, artificial joints, and plates for treating fractures. It is particularly useful in the maxillofacial regions, where the fact that it binds strongly to bone makes it suitable for widespread use in dental implants and reconstructive plates.

For bone defects in the head, neck, and maxillofacial regions, the grafting of pluripotent periosteal and bone marrow cells that can form bone and cartilage to regenerate bone in

${ }^{a}$ Division of Medicine for Function and Morphology of Sensor Organ, Dentistry and Oral Surgery, Osaka Medical College, 2-7 Daigaku-machi, Takatsuki City, Osaka, 569-8686, Japan. E-mail: ora071@osaka-med.ac.jp; Fax: +81-72-684-1422; Tel: +8172-683-1221

${ }^{b}$ Department of Biomedical Sciences, College of Life and Health Sciences, Chubu University, Aichi, Japan

'Osaka Yakin Kogyou Co., Ltd. Powder Processing Department, AM \& Medical Promotion Section, Osaka, Japan

${ }^{d}$ Division of Life Sciences, Anatomy and Cell Biology, Osaka Medical College, Osaka, Japan

${ }^{e}$ Department of Restrative Dentistry and Endodontology, Research Field in Dentistry, Medical and Dental Sciences Area, Research and Education Assembly, Kagoshima University, Kagoshima, Japan

${ }^{f}$ Department of Oral Pathology and Medicine, Graduate School of Medicine, Dentistry and Pharmaceutical Sciences, Okayama University, Okayama, Japan maxillofacial regions has been well reported. Good bone formation was observed in all cases. However, long-term followup revealed that the newly formed bone in these defects gradually atrophied and disappeared. ${ }^{\mathbf{1 - 4}} \mathrm{A}$ hard scaffold that maintains space for the newly formed bone over a long period is required to prevent this. Should this scaffold also possess high osteoinductive potential, this might lead to the development of optimal bone regeneration techniques, and in the dentistry field attention is currently focused on the guided bone regeneration (GBR) technique, which requires no grafted material. ${ }^{5}$ The GBR technique is used for small bone defects such as those encountered during periodontal treatment. ${ }^{6-11}$ However, it has been regarded as difficult to use for extensive bone defects and those with complex shapes. ${ }^{12}$

Although Ti is a highly biostable material, it is difficult to shape, and until recently it was impossible to freely create customized structures that recreate fine bone morphology or the structure of cancellous bone. Recently, however, threedimensional (3D) printing using pure powdered Ti selectively melted by laser irradiation has enabled the creation of $3 \mathrm{D}$ structures, and this technique is now being brought into use to form Ti devices of different shapes for clinical applications. ${ }^{13}$

Kokubo et al. were the first in the world to successfully impart high osteogenic capacity close to osteoinductive potential to $\mathrm{Ti}$ by implementing a special surface bioactivation treatment using mixed acids and heat. ${ }^{\mathbf{1 4 , 1 5}}$ 
In this study, the first of its kind worldwide, we treated a $\mathrm{Ti}$ mesh prepared by selective laser melting technique (SLM) with this mixed-acid and heat treatment, and used histological and radiographic observations to compare its osteogenic capacity in a rat calvarial bone defect model with that of Ti subjected to conventional surface treatments. We found that bone formed on this SLM-prepared Ti mesh, and that the amount of bone formation was greater on the mesh treated with mixed acids and heat.

\section{Materials and methods}

\subsection{Preparation of Ti meshes by SLM}

The designed Ti mesh data (Fig. 1A) was converted to the data in the STL (Standard Triangulated Language) format using 3D CAD software. The data were then converted using dedicated software to the data sliced at a fixed layer thickness $(30 \mu \mathrm{m})$. At the same time, a support part was designed and output as the same slice data (SLI format). The data converted to the SLI format were entered into a metal additive manufacturing machine (EOSINT M270: EOS GmbH Electro Optical Systems, Germany). The position to be shaped within the manufacturing range was determined with built-in software of the machine. According to the layer-by-layer two-dimensional (2D) data of the position and shape, the laser beam scanned on Ti powders layer to selectively melt and solidify. This operation was repeated for individual slice layers, which were stacked each other to prepare the designed Ti mesh (Fig. 1B).

\subsection{Surface activation treatments}

We subjected Ti meshes prepared by SLM to four different surface activation treatments. The Ti mesh samples were first immersed in acetone and ultrasonic cleaning was performed for $30 \mathrm{~min}$. They were then immersed in 2-propanol and ultrasonic cleaning was again performed for $30 \mathrm{~min}$, after which ultrasonic cleaning with ultra-pure water was performed for $30 \mathrm{~min}$.

2.2.1. Mixed-acid and heat treatment. Ultrasonic-cleaned $\mathrm{Ti}$ mesh samples were immersed in a mixed-acid solution containing a $1: 1$ by mass mixture of $66.3 \% \mathrm{H}_{2} \mathrm{SO}_{4}$ and $10.6 \% \mathrm{HCl}$ solutions. This was immersed in an oil bath maintained at $70{ }^{\circ} \mathrm{C}$ for $1 \mathrm{~h}$. During the immersion period, the samples were agitated at a rate of 120 times per min to treat the surface with the mixed acids. They were then gently rinsed in ultra-pure water for $1 \mathrm{~h}$, after which they were heated in air at a rate of increase of $5^{\circ} \mathrm{C}$ per minute from room temperature to $600{ }^{\circ} \mathrm{C}$, and maintained at this temperature for $1 \mathrm{~h}$. The samples were allowed to cool naturally in the furnace to complete the mixed-acid and heat treatment.

2.2.2. Alkali and heat treatment. Ti mesh samples were placed in 5.0 M NaOH solution, which was immersed in an oil bath maintained at $60{ }^{\circ} \mathrm{C}$ for $24 \mathrm{~h}$. During the immersion period, the samples were agitated at a rate of 120 times per min. They were then subjected to the same cleaning and heating process used for the mixed-acid and heat-treated samples to complete the $\mathrm{NaOH}$ and heat treatment.

2.2.3. Alkali, acid, and heat treatment. Ti mesh samples were first treated with $5.0 \mathrm{M} \mathrm{NaOH}$ solution and then placed in $50 \mathrm{mM} \mathrm{HCl}$ solution. This was immersed in an oil bath maintained at $40{ }^{\circ} \mathrm{C}$ for $24 \mathrm{~h}$. During the immersion period, the samples were agitated at a rate of 120 times per min. They were then subjected to the same cleaning and heating process used for the mixed-acid and heat-treated samples to complete the $\mathrm{NaOH}, \mathrm{HCl}$, and heat treatment.

2.2.4. Alkali, $\mathrm{CaCl}_{2}$, heat, and hot water treatment. Ti mesh samples were first treated with $5.0 \mathrm{M} \mathrm{NaOH}$ solution and then placed in $100 \mathrm{mM} \mathrm{CaCl}$ solution. This was immersed in an oil bath maintained at $40{ }^{\circ} \mathrm{C}$ for $24 \mathrm{~h}$. During the immersion period, the samples were agitated at a rate of 120 times per min. They were then subjected to the same cleaning and heating process used for the mixed-acid and heat-treated samples. After this the samples

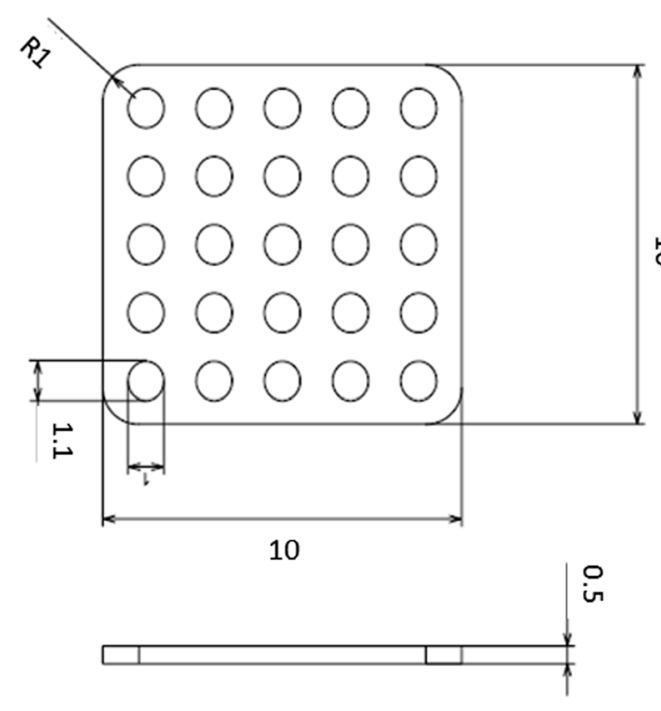

A

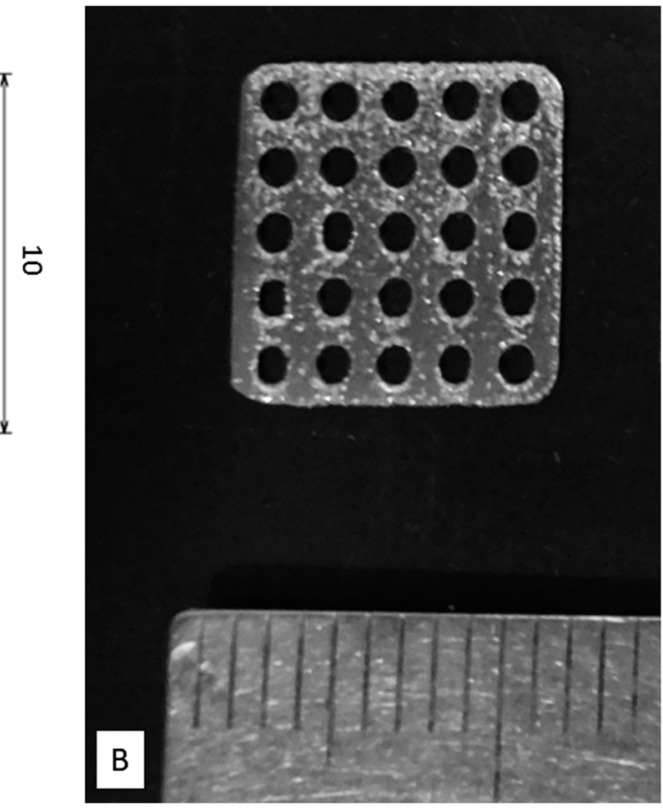

Fig. 1 Titanium mesh prepared for this study. (A) Diagram showing dimensions. (B) Photograph of actual sample. 
were immersed in hot water maintained at $80{ }^{\circ} \mathrm{C}$ for $24 \mathrm{~h}$, during which time were agitated at a rate of 120 times per min to complete the $\mathrm{NaOH}, \mathrm{CaCl}_{2}$, heat, and hot water treatment.

2.2.5. No treatment. Untreated Ti mesh samples were also prepared.

\subsection{Evaluation of bioactivity of treated Ti mesh samples}

The five different types of Ti mesh samples subjected to surface activation treatments using Kokubo et al.'s method described above were immersed for $24 \mathrm{~h}$ at $36.5{ }^{\circ} \mathrm{C}$ in simulated body fluid (SBF) with inorganic ion concentrations closely resembling those of the human body. They were then coated with $\mathrm{Pt} / \mathrm{Pd}$, and apatite formation was observed using a field-emission-type scanning electron microscope (SEM) at $15 \mathrm{kV}$ acceleration voltage.

\subsection{Animal experiment}

Thirty four Ti meshes prepared by SLM were used in the following animal experiment. These experiments were carried out in strict accordance with the recommendations in the Guide for the Care and Use of Laboratory Animals of the National Institutes of Health. The protocol was approved by the Animal Research Committee, Osaka Medical College, Japan (Permit Number: 27110). All surgery was performed at Graduate School of Medicine, Osaka Medical College. All efforts were made to minimize suffering.

Fig. 2 shows the operating procedure for creating the bone defects in this study. Rats that were sedated with isoflurane inhalation anesthesia intraperitoneally. Using a \#15 surgical blade, an incision was made in the skull. Subsequently, full thickness epidermal, hypodermal, and periosteum flaps were then elevated, and the skull was exposed. After marking the defect perimeter using a template, a bone defect (about diameter of $5 \mathrm{~mm}$ and $1.5 \mathrm{~mm}$ deep) was formed along the template with a dental round bar under water irrigation (Fig. 2A). A Ti mesh was fixed to the bone with a $1 \mathrm{~mm}$ diameter microscrew (KLS Martin Group, Osaka, Japan) to completely cover the defect. The periosteum and skin were sutured with a 7-0 absorbable thread and a 3-0 silk thread, respectively, to close the wound (Fig. 2B).

Defect site tissue samples were obtained 2 weeks, 4 weeks, and 7 weeks after the operation.

\subsection{Radiographic observations}

The process of bone formation in bone defects immediately below the Ti mesh was examined radiographically by micro-
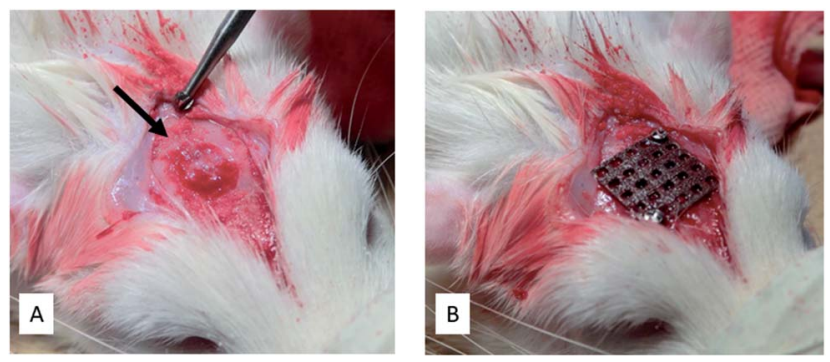

Fig. 2 Intraoperative photographs. (A) Bone defect created (arrow). (B) Bone defect covered and fixed with a titanium mesh. computed tomography (micro-CT) using a Latheta LCT-200 (Hitachi Aloka Medical, Ltd., Tokyo, Japan). Imaging was performed at a tube voltage of $50 \mathrm{kV}$, tube current of $2 \mathrm{~mA}$, pixel size of $48 \mu \mathrm{m}$, and slice thickness of $96 \mu \mathrm{m}$.

The scanned images were reconstructed three-dimensionally using VGSTUDIO MAX 2.0 3D reconstruction software (Volume Graphics, Heidelberg, Germany).

\subsection{Histological observation}

The tissue samples were fixed with a $20 \%$ formalin solution. The fixed samples were dehydrated/defatted with ethanol and acetone. Thereafter, the tissue samples were immersed in methyl methacrylate (MMA) to prepare MMA resin blocks. Frontal sections were prepared by cutting the block using a micro-cutting machine (BS-300CL/WXAKT) and a micro-grinding machine (MG-400CS/EXAKT) to pass through the center of the bone defect created. About $40 \mu \mathrm{m}$-thick ground slides were prepared.

The ground slides were subjected to xylene treatment to remove resin and toluidine blue staining before being sealed.

The center of the bone defect was observed in the frontal section with an optical microscope, Nikon ECLIPSE Ci (Nikon, Japan). The ratio of the new bone area to the bone defect area was determined using image analysis software, Nikon NISElements Basic Research (Nikon, Japan) as shown in Fig. 3, and compared between the mixed-acid and heat-treated group and other groups.

\subsection{Statistical analysis}

Comparisons of the amounts (percentages) of new bone at 2, 4, and 7 weeks postoperatively were made using analysis of variance for overall comparisons between all five groups and Dunnett's multiple-comparison test for paired comparisons between the mixed-acid and heat-treated group and other groups. The statistical software used was SAS 9.4 (SAS Institute Inc., Cary, NC, USA), and any difference with $p<0.05$ was considered significant.

\section{Results}

\subsection{Bioactivity}

Fig. 4 shows the results of SEM observations of the surfaces of the Ti mesh samples after immersion in SBF. The untreated $\mathrm{Ti}$ did not exhibit any deposition on its surface in SBF, whereas

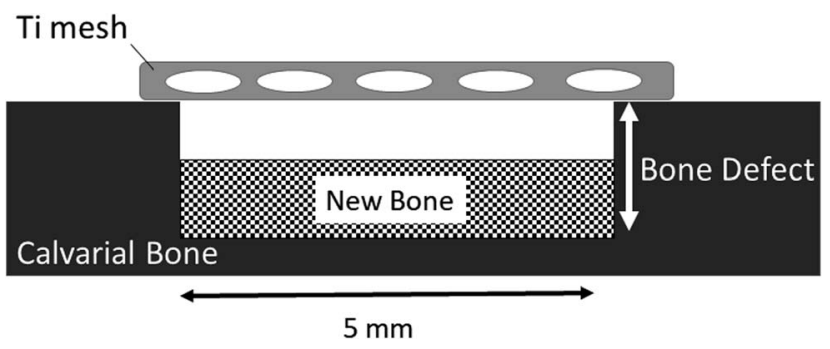

Fig. 3 Method to calculate the ratio of the amount of new bone formation in bone defects. The ratio (\%) of the new bone area to the bone defect area is determined, and $t$ test $(p<0.05)$ is used for comparisons. 


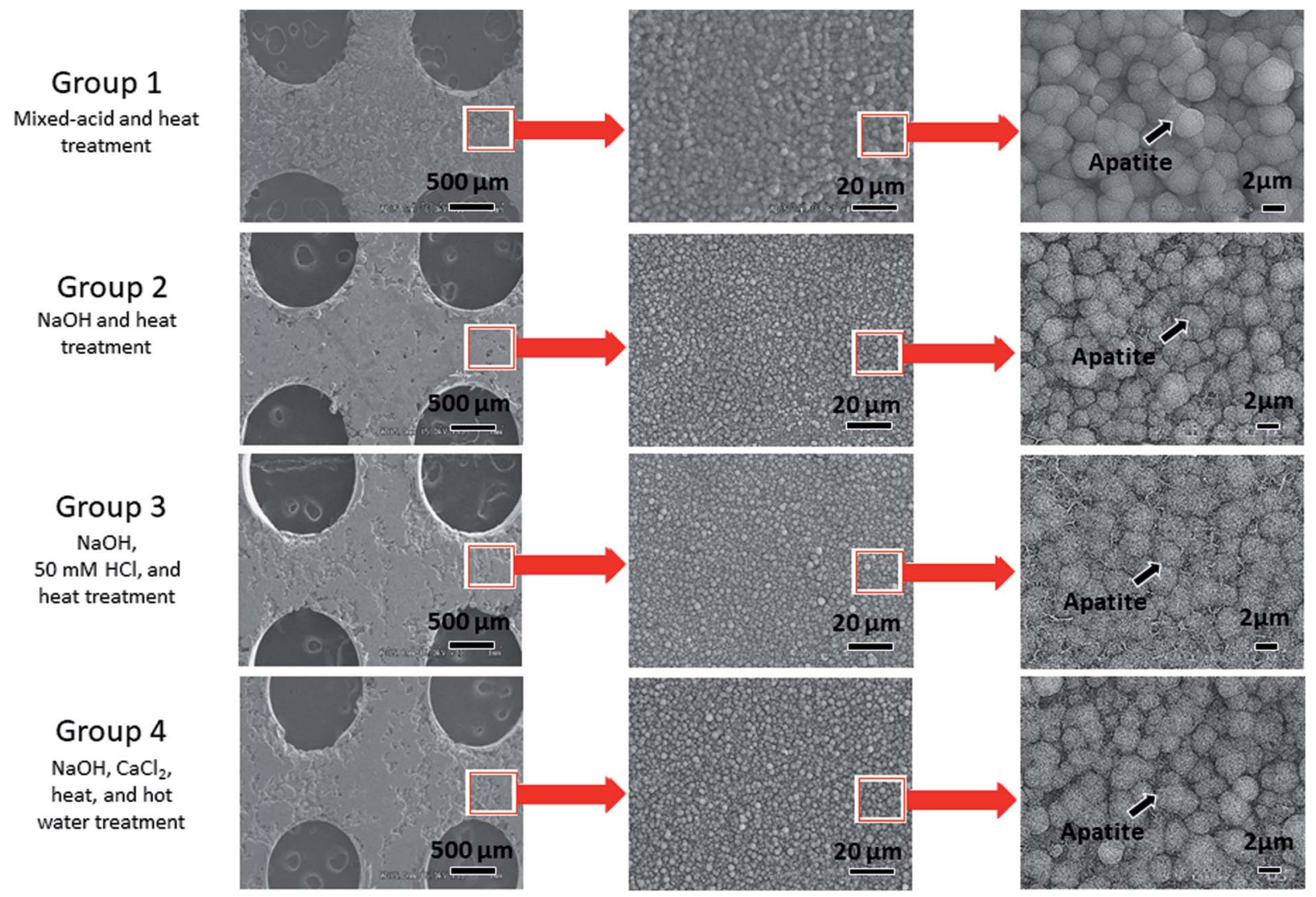

Fig. 4 Electron microscopy images of the surfaces of titanium mesh samples immersed for $24 \mathrm{~h}$ in simulated body fluid after surface activation treatment.

spherical particles taking apatite structure (Fig. 5) were formed on the surfaces of all the samples that had undergone surface activation treatments. Microscale apatite formation was present on the surface of the mixed-acid and heat-treated Ti, and nanoscale apatite formation on the surfaces of the samples that had undergone other treatments.

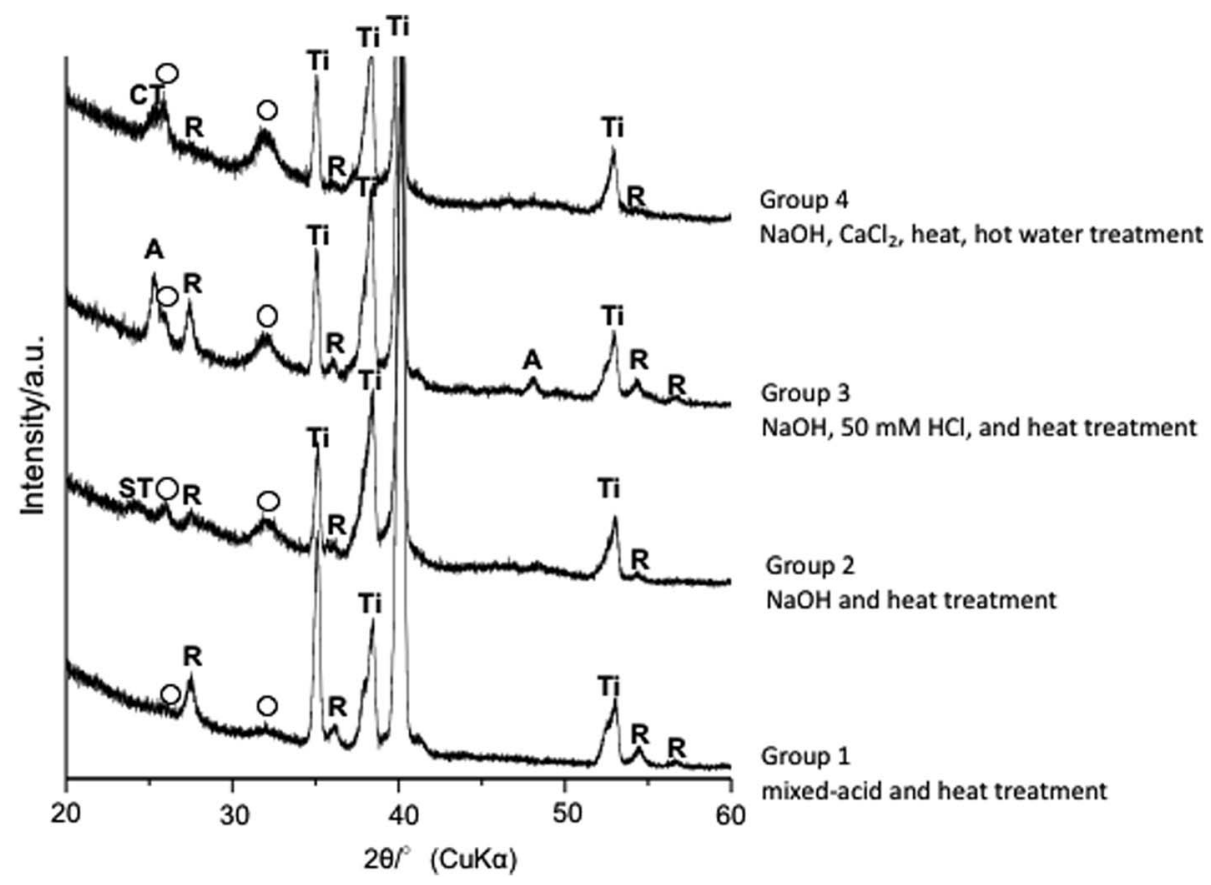

Fig. 5 Thin-film X-ray diffraction of the surfaces of titanium mesh samples immersed for $24 \mathrm{~h}$ in simulated body fluid after surface activation treatment. Ti: $\alpha$-Ti, R: rutile, A: anatase, ST: sodium titanate, CT: calcium titanate $\&$ CIR; $(O)$ apatite. 




Fig. 6 Micro-computed tomography images. The prepared bone defects are enclosed by dotted lines. (A) Mixed-acid and heat treatment, (B) $\mathrm{NaOH}$ and heat treatment, (C) $\mathrm{NaOH}, 50 \mathrm{mM} \mathrm{HCl}$, and heat treatment, (D) $\mathrm{NaOH}, \mathrm{CaCl}_{2}$, heat, and hot water treatment, (E) no treatment.

\subsection{Radiographic observations of bone repair}

Micro-CT images revealed good bone repair in rats implanted with mixed-acid and heat-treated Ti mesh (Fig. 6A).

Bone defects were present in the rats implanted with Ti subjected to other treatments (Fig. 6B-E).

\subsection{Effect of bioactivation treatment on bone repair}

Histological observations of undecalcified ground sections revealed good bone repair in the rats implanted with mixed-acid and heat-treated Ti mesh, with the bone defect almost entirely covered with new bone immediately below the mesh (Fig. 7A). Bone defects of varying extents were still present in rats in the other groups (Fig. 7B-E).

There were significant differences between all five groups in the proportions of new bone within the defects at 2 weeks postoperatively, with significantly more new bone present in rats implanted with mixed-acid and heat-treated Ti mesh than in those in all the other groups (Fig. 8).



Fig. 7 Photograph of an undecalcified ground sample. The bone defect created is surrounded by a dotted line, and newly generated bone is indicated by an asterisk (*). (A) Mixed-acid and heat treatment, (B) $\mathrm{NaOH}$ and heat treatment, (C) $\mathrm{NaOH}, 50 \mathrm{mM} \mathrm{HCl}$, and heat treatment, (D) $\mathrm{NaOH}, \mathrm{CaCl}_{2}$, heat, and hot water treatment, (E) no treatment. 


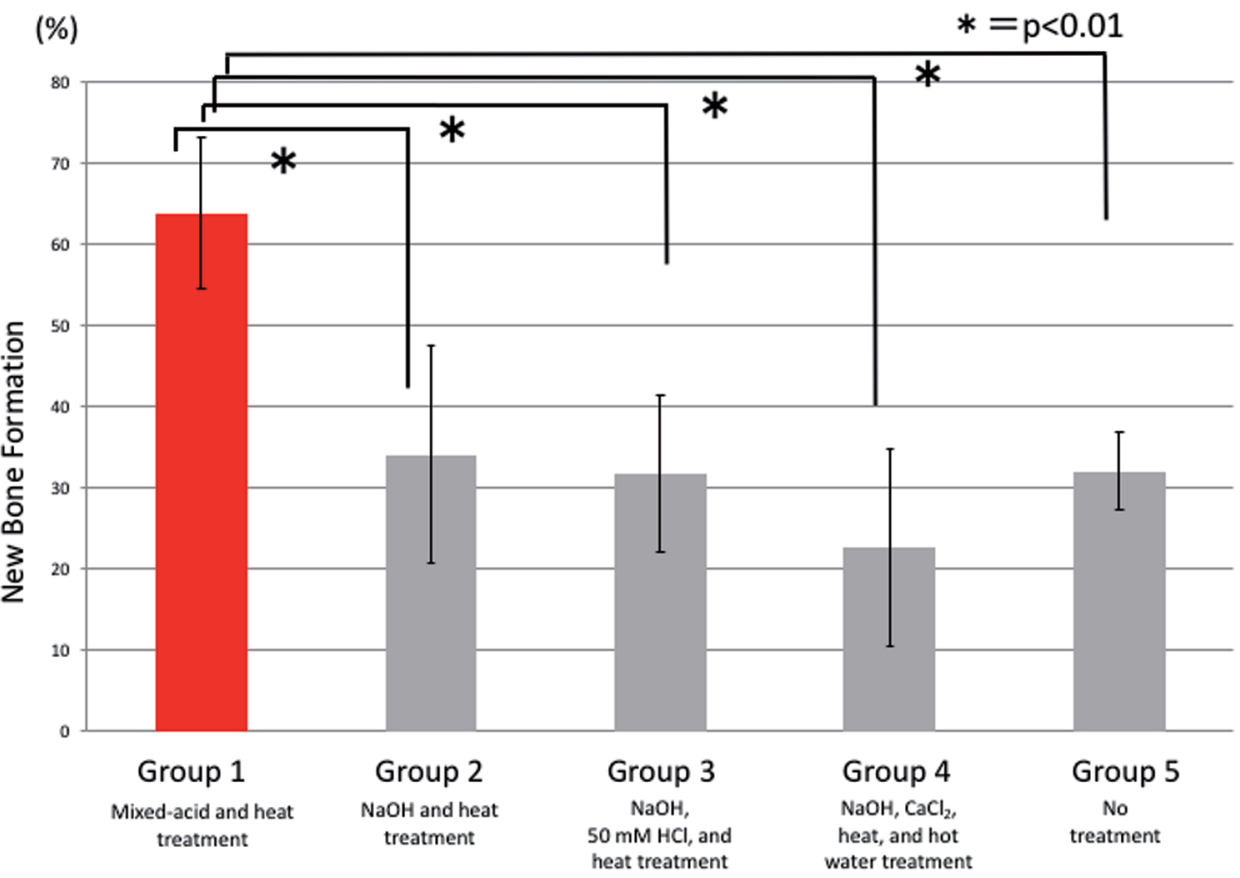

Fig. 8 Ratios (\%) of newly formed bone 2 weeks after surgery.
(\%)
$*=p<0.01$



Fig. 9 Ratios (\%) of newly formed bone 4 weeks after surgery.

At 4 weeks postoperatively there were significant differences between all five groups, with significantly more new bone present in rats implanted with mixed-acid and heat-treated $\mathrm{Ti}$ mesh than in those in all the other groups (Fig. 9).

At 7 weeks postoperatively there were also significant differences between all five groups. There was significantly more new bone present in rats implanted with mixed-acid and heat-treated $\mathrm{Ti}$ mesh than in those in the $\mathrm{NaOH}$ and heattreated group and the $\mathrm{NaOH}, \mathrm{CaCl}_{2}$, heat, and hot-watertreated group (Fig. 10).

\section{Discussion}

In this study, we created calvarial bone defects in rats and covered them with Ti mesh prepared by SLM that had been treated to activate the surface using several different methods, in the first study in the world to evaluate the in vivo osteogenic capacity of Ti mesh prepared by SLM and given different surface treatments. We found that the highest osteogenic capacity was provided by mixed-acid and heat treatment. The next highest osteogenic capacity was provided by treatment with $\mathrm{NaOH}$, 




Fig. 10 Ratios (\%) of newly formed bone 7 weeks after surgery.

$50 \mathrm{mM} \mathrm{HCl}$, and heat, followed by no treatment, treatment with $\mathrm{NaOH}, \mathrm{CaCl}_{2}$, heat, and hot water, and treatment with $\mathrm{NaOH}$ and heat, in that order. Previous studies of the spine ${ }^{16}$ and femur ${ }^{17}$ have all found that alkali treatment resulted in significantly higher osteogenic capacity compared with no treatment. The reason that alkali-treated Ti mesh exhibited lower osteogenic capacity than untreated mesh in this study may have been that when mesh is implanted into the femoral bone or spine it is surrounded by large amounts of blood and other body fluids, whereas the cranium has a poor blood supply and is not well perfused with body fluids. Alkali treatment initiates apatite formation by the elution of $\mathrm{Na}$ and $\mathrm{Ca}$ ions. In environments with little body fluid, however, it is possible that the local $\mathrm{pH}$ may increase, reducing cell activity and affecting bone formation. This may also be inferred from the fact that Takemoto et al. found no osteoinduction in the central areas of porous bodies implanted in femoral bone. ${ }^{17}$

The GBR technique is an effective method of bone regeneration that is used in clinical practice. Its concept involves physically sealing off the area in which bone formation is desired, with the aim of preventing other tissues, particularly soft tissue, from interfering with the formation of new bone. At the same time, it also induces the formation of new bone. The use of a histocompatible barrier membrane with osmotic and air permeability to create the space for bone regeneration thus prevents the invasion of competing non-bone tissue into the bone defect and facilitate new bone tissue formation by promoting the proliferation of cells derived from the surrounding bone tissue. ${ }^{18,19}$ Karaji et al. reported that surface activation treatment increased the bioactivity of porous $\mathrm{Ti}$ granules. So they thought that surface activation treatment may thus promote bone formation when Ti, which is highly histocompatible, is used as a barrier membrane. ${ }^{20}$
A comparison of rats implanted with acid-treated and alkali-treated $\mathrm{Ti}$ showed that osteogenic capacity was higher after acid treatment. This result was consistent with those of Kokubo et al., who found that acid and heat-treated Ti had higher osteogenic capacity than Ti treated with $\mathrm{NaOH}$ and heat. ${ }^{14,15}$

After 2 and 4 weeks postoperatively, Ti treated with mixed acids and heat provided better bone formation at an early stage than did Ti treated with $\mathrm{NaOH}, 50 \mathrm{mM} \mathrm{HCl}$, and heat. Thin-film $\mathrm{X}$-ray diffraction showed apatite formation on the surface of $\mathrm{Ti}$ in all groups (Fig. 5) within $24 \mathrm{~h}$ in SBF as reported in previous reports. ${ }^{21,22}$

One difference between these treatments is that apatite formation on a microscale was evident on the surface of mixedacid and heat-treated $\mathrm{Ti}$ in SBF, whereas for Ti treated with $\mathrm{NaOH}, 50 \mathrm{mM} \mathrm{HCl}$, and heat only nanoscale apatite formation was evident. However, the association with the difference in bone formation seen in this study is unclear.

Mixed-acid and heat-treated Ti mesh exhibited early high osteogenic capacity after 2 weeks, and this was maintained until 7 weeks postoperatively (Fig. 11). The surface properties of the Ti mesh may thus have contributed to the biological response of cells involved in bone formation, such as osteoblasts and osteoclasts.

A certain degree of bone formation was also evident even when untreated Ti was used. This may have been because the method used to shape the Ti was different from that of previous studies. The SLM involves cooling after heating to a high temperature, which may result in a rough surface and it is also possible that an oxidized layer may have formed on the surface. ${ }^{23}$ The fact that Ti mesh prepared by SLM possesses osteogenic capacity is not inconsistent with our previous report. $^{24}$ 


\section{(\%)}



Fig. 11 Changes in ratio of newly formed bone 2 weeks, 4 weeks, and 7 weeks after surgery.

In clinical practice, bone defect repair is necessary not only in oral surgery but also in other fields such as orthopedic surgery and plastic surgery. Bone defects come in many shapes and sizes, and may be complex in form. Although Ti is highly biostable, it is difficult to form into a desired shape, and until recently it was impossible to create customized structures that recreate fine bone morphology or the structure of cancellous bone. Recently, however, it has become possible to use pure powdered Ti selectively melted by laser irradiation to create 3D structures on a $0.5 \mathrm{~mm}$ scale, and this technique is now being brought into use to form Ti devices of different shapes. ${ }^{7}$ However, little is known about the process of bone formation around such structures.

As described above, in this study we carried out GBR technique using Ti mesh prepared by SLM and evaluated its osteogenic capacity, finding that it exhibited good osteogenic capacity. This result suggests that this material may be usable for bone defects that are complex in shape.

Previous studies in the field of metal materials for bone repair have investigated the effect of surface activation treatment with acid or alkali to increase the speed and strength of bonding between bone and $\mathrm{Ti}^{8}{ }^{8}$ However, no treatment has been found to impart high osteogenic capacity to Ti surfaces. Nor has any previous study compared the osteogenic capacity in vivo provided by different surface activation treatments. Mixed-acid and heat-treated Ti metal acidifies the environment close to the surface in SBF, with the formation of $\mathrm{Ti}-\mathrm{OH}$ groups on the surface. In this acidic environment the $\mathrm{Ti}-\mathrm{OH}$ groups are positively charged, binding to negatively charged phosphate ions in body fluid. When this reaction proceeds, the surface becomes negatively charged and binds to positively charged calcium ions, resulting in the formation of amorphous calcium phosphate which is later transformed to stable apatite. Kokubo et al. reported such apatite formation in SBF. In this study, we compared the osteogenic capacity provided by different forms of surface treatment by carrying out observations using a rat calvarial bone defect model. We found that Ti mesh treated with mixed acids and heat exhibited the highest osteogenic capacity.
We intend to carry out further studies to evaluate the osteogenic capacity of mixed-acid and heat-treated prepared $\mathrm{Ti}$ in larger bone defects and to investigate its performance in regenerating bone in sites of complex bone defects such as the temporomandibular joint and mandible by utilizing the freedom to design detailed structures provided by the SLM, and to investigate their clinical utility.

\section{Conclusion}

Our results showed that Ti mesh prepared by SLM promoted bone formation whether or not it underwent any surface activation treatment. Of the various techniques used, treatment with mixed acids and heat demonstrated higher osteogenic capacity compared with those provided by other surface activation treatments. Our study suggested that it may be possible to use Ti artificial bone combining these techniques to repair complex bone defects more completely.

\section{Conflicts of interest}

There are no conflicts to declare.

\section{Acknowledgements}

This work was supported by JSPS KAKENHI Grant Number JP18K17185.

\section{References}

1 R. Quarto, M. Mastrogiacomo, R. Cancedda, S. M. Kutepov, V. Mukhachev, A. Lavroukov, E. Kon and M. Marcacci, N. Engl. J. Med., 2001, 344, 385-386.

2 M. Iino, M. Fukuda, H. Nagai, Y. Hamada, H. Yamada, K. Nakaoka, Y. Mon, D. Chikazu, H. Saijo, I. Seto, K. Ohkubo and T. Takato, Oral Surg. Oral Med. Oral Pathol. Oral Radiol. Endod, 2009, 107, e1-e8.

3 R. Mowlem, Lancet, 1944, 244, 746-748. 
4 W. Axhausen, J. Bone Jt. Surg., Am., 1956, 38, 593-600.

5 A. H. Melcher, J. Periodontal, 1976, 47, 256-260.

6 Y. D. Rakhmatia, Y. Ayukawa, A. Furuhashi and K. Kayano, J. Prosthodont Res., 2013, 57, 3-14.

7 W. Becker, B. E. Becker, J. Mellonig, R. G. Caffesse, K. Warrer, J. G. Caton and T. Reid, J. Periodontol, 1996, 67, 641-649.

8 C. H. Schopper, W. Goriwoda, D. Moser, E. Spassova, F. Watzinger and R. Ewers, Oral Maxillofac. Surg. Clin. North Am., 2001, 13, 449-458.

9 N. U. Zitzmann, R. Naef and R. Scharer, Int. J. Oral Maxillofac. Implants, 1997, 12, 844-852.

10 J. J. Sevor, R. M. Meffert and R. J. Cassingham, Int. J. Periodontics Restorative Dent., 1993, 13, 71-83.

11 B. S. Black, M. E. Gher, J. B. Sandifer, S. E. Fucini and A. C. Richardson, J. Periodontol, 1994, 65, 598-604.

12 H. L. Wang and L. Boyapati, Implant Dent., 2016, 15, 8-17.

13 L. Mullen, R. C. Stamp, W. K. Brooks, E. Jones and C. J. Sutcliffe, J. Biomed. Mater. Res., Part B, 2009, 89, 325334.

14 T. Kokubo and S. Yamaguchi, Front. Bioeng. Biotechnol., 2015, 3, 176.

15 T. Kawai, M. Takemoto, S. Fujibayashi, H. Akiyama, M. Tanaka, S. Yamaguchi, D. K. Pattanayak, K. Doi, T. Matsushita, T. Nakamura, T. Kokubo and S. Matsuda, PLoS One, 2014, 10, e88366.
16 T. Kokubo and S. Yamaguchi, Adv. Biomater., 2012, 12, B579B591.

17 M. Takemoto, S. Fujibayashi, M. Neo, J. Suzuki, T. Matsushita, T. Kokubo and T. Nakamura, Biomaterials, 2006, 27, 2682-2691.

18 D. Buser, C. Dahlin and R. K. Schenk, Guided Bone Regeneration in Implant Dentistry, Quintessence Publishing Co., 1992.

19 S. Cho, J. Kyushu Dent. Soc., 1998, 52, 161-173.

20 Z. G. Karaji, B. Houshmand and S. Faghihi, Int. J. Oral Maxillofac. Implants, 2016, 31, 1274-1280.

21 T. Kokubo, D. K. Pattanayak, S. Yamaguchi, H. Takadama, T. Matsushita, T. Kawai, M. Takemoto, S. Fujibayashi and T. Nakamura, J. R. Soc., Interface, 2010, 7, 503-513.

22 S. Yamaguchi, H. Takadama, T. Matsushita, T. Nakamura and T. Kokubo, J. Ceram. Soc. Jpn., 2009, 117, 1126-1130.

23 M. Tsukanaka, S. Fujibayashi, M. Takemoto, T. Matsushita, T. Kokubo, T. Nakamura, K. Sasaki and S. Matsuda, Dent. Mater. J., 2016, 35, 118-125.

24 K. Yamamoto, S. Yamaguchi, T. Matsushita, S. Mori, H. Kitagaki, H. Yoshimura, K. Sano, A. Sunano, Y. Nakajima, H. Nakano and T. Ueno, J. Hard Tissue Biol., 2017, 26, 257-260. 